\title{
Absence of species specificity for mammalian sperm capacitation in vivo
}

\author{
Patricia M. Saling* and J. M. Bedford \\ Departments of Anatomy and Obstetrics and Gynecology, Cornell University Medical College, \\ New York, New York 10021, U.S.A.
}

\begin{abstract}
Summary. Spermatozoa and eggs of one species were transferred into the oviducts of other species to examine the specificity of mammalian sperm capacitation in vivo. Using mice, rats, hamsters and rabbits, 11 different combinations of gametes and host were tested, with cumulus-intact and cumulus-free eggs being placed in opposite oviducts of a recipient. In all combinations compatible with the maintenance of sperm motility over a period sufficient for capacitation, fusion occurred between homologous gametes without regard to the identity of the host environment. The period required for capacitation, as judged by the timing of egg penetration, was a function of the specific character of the spermatozoon more than of the 'oestrous' oviduct. Fertilization level was not enhanced significantly by the presence of the cumulus oophorus, with the single striking exception of mouse eggs in the hamster. Sperm viability was not always optimal in a foreign tract; mouse and hamster spermatozoa became immotile within $2 \mathrm{~h}$ in the rabbit. Despite this limitation on sperm viability, some mouse eggs were fertilized in the rabbit, indicating that capacitation is possible even when the environment is suboptimal for motility maintenance. Therefore, while the results indicate that there is no specificity for capacitation as such, it should not be inferred that there is a total absence of specificity in the relationship between the female reproductive tract and gametes.
\end{abstract}

\section{Introduction}

Capacitation is a process which occurs naturally in the female reproductive tract, conferring upon mammalian spermatozoa the ability to fertilize homologous eggs. Although originally described nearly 30 years ago (Austin, 1951, 1952; Chang, 1951), the biological significance of capacitation remains unknown, and the mechanisms and determinants involved in the process are still vague. One particular aspect of capacitation that has not been examined critically is the ability of a heterologous reproductive tract to support sperm capacitation. Species specificity of capacitation is certainly not an element when species are sufficiently similar to permit hybrid fertilization in vivo (Chang \& Hancock, 1967); nor does it play a part in capacitation in vitro, tested by fertilization in vitro. However, the finding that rabbit spermatozoa are not completely capacitated in the rat uterus, even over prolonged periods, suggested that at least one phase of this process in vivo might be species specific (Bedford \& Shalkovsky, 1967). It was later suggested (Hunter, 1969) that the rodent uterus alone, rather than the uterus plus oviduct, may be unable to support complete capacitation even of homologous spermatozoa. We have therefore addressed this question of the species specificity of capacitation directly by transferring spermatozoa and eggs of one species into the female tract of a second species.

* Present address: The Population Council, 1230 York Avenue, New York, New York 10021, U.S.A. 


\section{Materials and Methods}

Spermatozoa were deposited into the ovarian bursae or oviducts of a heterologous, peri-ovulatory female. After an interval approximately equivalent to that required for capacitation in vivo in the homologous species, freshly ovulated eggs from donors homologous to the spermatozoa were instilled through the ostium into the host's oviducts. One oviduct received eggs surrounded by cumulus cells, while the contralateral side received cumulus-free eggs. The tubal eggs were recovered by flushing the host's oviducts at 3-5 h after transfer.

For the experiments presented in Table 1, mouse and hamster spermatozoa were released at $37^{\circ} \mathrm{C}$ under sterile silicone oil by mincing the excised epididymal tails of mature males. Mouse

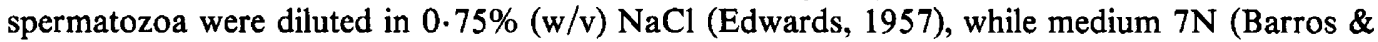
Berrios, 1977) was used for the hamster. Spermatozoa from these two species were inseminated without further preparation. Ejaculated rabbit spermatozoa were prepared for insemination by centrifugation through $10 \%$ Ficoll (Sigma) in Tyrode solution $(\mathrm{NaCl}, 137 \mathrm{~mm} ; \mathrm{KCl}, 3 \mathrm{~mm}$; $\mathrm{CaCl}_{2}, 2 \mathrm{mM} ; \mathrm{NaH}_{2} \mathrm{PO}_{4}, 0.4 \mathrm{~mm} ; \mathrm{MgCl}_{2}, 0.2 \mathrm{~mm} ; \mathrm{NaHCO}_{3}, 12 \mathrm{mM}$; glucose, $5.56 \mathrm{mM}$ ) for 10 $\mathrm{min}$ at $700 \mathrm{~g}$ to remove seminal plasma, and resuspended at a concentration of $0.5-4.0 \times 10^{9}$ cells $/ \mathrm{ml}$ in Tyrode supplemented with penicillin $(60 \mathrm{i} . \mathrm{u} . / \mathrm{ml})$ and streptomycin $(60 \mu \mathrm{g} / \mathrm{ml})$. The host females, used at the time of ovulation (achieved naturally for rats, by mating for rabbits, or by stimulation with PMSG, followed 50-56 h later with hCG in mice and hamsters), were anaesthetized (pentobarbitone sodium or tribromoethanol) and the oviducts were exposed by flank incision. Spermatozoa were deposited with a micropipette into the ovarian bursa of mice, hamsters and rats, and directly into the oviducal ampulla in rabbits. A sperm suspension of $10^{6}$ cells in a volume of $15-40 \mu \mathrm{l}$ was used for insemination. Regardless of the host, incubation times in vivo were constant for the species of spermatozoa inseminated: $14 \mathrm{~h}$ for the rabbit, $6 \mathrm{~h}$ for the hamster, and 2-3 h for the mouse, except when used in the rabbit when incubation time was reduced to $1-1.5 \mathrm{~h}$ (see below). Ovulated eggs were recovered in media optimal for each species: Medium CM (Saling, Storey \& Wolf, 1978) for mouse eggs; Medium $7 \mathrm{~N}$ for hamster eggs; and Tyrode's solution with $10 \%$ heated rabbit serum for rabbit eggs. At an appropriate interval after insemination in vivo, cumulus-intact eggs were transferred into one oviduct, while the contralateral side received eggs denuded of cumulus cells by brief $(5-10 \mathrm{~min})$ exposure to hyaluronidase $(0 \cdot 1 \%$, Sigma, Type 1$)$. Corona radiata cells surrounding rabbit eggs are not removed with this treatment, and were present during the experiments. Recipients were killed 4-5 $\mathrm{h}$ later. The eggs were recovered by flushing the excised oviducts, mounted on slides and examined with phase-contrast optics $(\times 400)$ following aceto-lacmoid staining (Toyoda \& Chang, 1974). Eggs were considered penetrated if spermatozoa were present only in the perivitelline space, and fertilized when the fertilizing sperm tail(s) and sperm head(s) or pronuclei could be identified in the egg cytoplasm.

Table 1. The ability of a heterologous reproductive tract to support capacitation as indicated by the number of eggs penetrated/total number of eggs

\begin{tabular}{lccccc}
\hline & & \multicolumn{4}{c}{ Host } \\
\cline { 3 - 6 } Gametes & $\begin{array}{c}\text { Cumulus } \\
\text { cells }\end{array}$ & Mouse & Hamster & Rabbit & Rat \\
\hline Mouse & + & $56 / 64$ & $52 / 90^{*}$ & $12 / 137 \dagger$ & $37 / 42$ \\
& - & $66 / 78$ & $0 / 73^{*}$ & $7 / 110^{\dagger}$ & $40 / 45$ \\
Hamster & + & $24 / 43$ & $50 / 73$ & $0 / 42 \dagger$ & $31 / 47$ \\
& - & $25 / 48$ & $41 / 65$ & $0 / 36 \dagger$ & $34 / 51$ \\
Rabbit & $-\ddagger$ & $9 / 9$ & $20 / 20$ & $48 / 54 \S$ & \\
\hline
\end{tabular}

* See Table 2.

+ Spermatozoa lost motility within $2 \mathrm{~h}$ of transfer to host.

$\mp$ Corona radiata cells present.

$\S$ Data from Bedford \& Cross (1978). 
For the experiments presented in Table 2, mouse spermatozoa were collected as described above. Some spermatozoa (Exp. A, Table 2) were diluted, as before, in a small volume of $0.75 \%$ $\mathrm{NaCl}$ and used immediately, but others (Exp. B, Table 2) were diluted in Medium CM to a concentration of $10^{7}$ cells $/ \mathrm{ml}$. After incubation for $1-2 \mathrm{~h}$ to induce capacitation in vitro, the spermatozoa were layered onto a BSA cushion (medium CM plus $10 \%$ BSA) and centrifuged for $5 \mathrm{~min}$ at $700 \mathrm{~g}$. The supernatant was discarded and the loose pellet resuspended gently in Medium CM. The sperm suspension was used immediately for insemination $\left(1.0-1.6 \times 10^{6}\right.$ spermatozoa in Exp. A and 2.5-4.0 $\times 10^{6}$ spermatozoa in Exp. B) into the ovarian bursa of recipient hamsters. Mouse eggs (cumulus-intact eggs on one side and cumulus-free eggs on the other side) were transferred directly into the oviducts $2 \mathrm{~h}$ later. Eggs were recovered and fertilization assessed as described above.

Table 2. Fertilization of mouse gametes in the hamster oviduct

\begin{tabular}{|c|c|c|c|c|c|}
\hline & \multirow[b]{2}{*}{$\begin{array}{l}\text { No. of } \\
\text { exps }\end{array}$} & \multicolumn{2}{|c|}{ Eggs penetrated (\%) } & \multicolumn{2}{|c|}{ Eggs fertilized (\%) } \\
\hline & & $\begin{array}{c}\text { Cumulus- } \\
\text { intact }\end{array}$ & $\begin{array}{l}\text { Cumulus- } \\
\text { free }\end{array}$ & $\begin{array}{c}\text { Cumulus- } \\
\text { intact }\end{array}$ & $\begin{array}{l}\text { Cumulus- } \\
\text { free }\end{array}$ \\
\hline $\begin{array}{c}\text { A. Fresh epididymal } \\
\text { spermatozoa }\end{array}$ & 5 & $\begin{array}{r}52 / 90 \\
(58)\end{array}$ & $\begin{array}{c}0 / 73 \\
(0)\end{array}$ & $\begin{array}{r}40 / 90 \\
(44)\end{array}$ & $\begin{array}{c}0 / 73 \\
(0)\end{array}$ \\
\hline $\begin{array}{l}\text { B. Spermatozoa } \\
\text { capacitated } \\
\text { in vitro }\end{array}$ & 10 & $\begin{array}{c}60 / 117 \\
(51)\end{array}$ & $\begin{array}{l}0 / 89 \\
(0)\end{array}$ & $\begin{array}{c}54 / 117 \\
(46)\end{array}$ & $\begin{array}{c}0 / 89 \\
(0)\end{array}$ \\
\hline
\end{tabular}

To verify the occurrence of capacitation in vitro, the same centrifuged sperm suspension was used to inseminate mouse eggs in vitro (Wolf \& Inoue, 1976). The fertilization level $2 \mathrm{~h}$ later as well as the stage of sperm penetration were used as indicators of the capacitated state. Only those experiments in which capacitation was achieved unequivocally were included in the data.

\section{Results}

The results presented in Table 1 indicate that complete and functional capacitation may be achieved by spermatozoa in a heterologous female tract. In the combinations compatible with sperm survival for a sufficient period, substantial fertilization levels were obtained. Of the three species examined, the highest fertilization levels were found with rabbit gametes: all of 20 rabbit eggs were penetrated in the hamster, and all of 9 rabbit eggs were penetrated in the mouse. The penetration of numerous spermatozoa into the perivitelline space is not uncommon in rabbit eggs under standard conditions, but most of the rabbit eggs recovered from foreign tracts displayed an exceptionally high $(50->100)$ number of perivitelline spermatozoa, obscuring the confident assessment of vitelline penetration in occasional eggs.

Hamster eggs were fertilized readily in both the rat and mouse: $30 / 47$ eggs (64\%) were fertilized in the rat, while $19 / 43$ eggs $(44 \%)$ were fertilized in the mouse. Similar levels were obtained with cumulus-intact and cumulus-free hamster eggs. Capacitation of hamster spermatozoa could not be examined in the rabbit since these spermatozoa became immotile within $2 \mathrm{~h}$ of transfer to the rabbit uterus or oviduct. The adverse environment was not induced by the experimental procedure, since rabbit eggs were fertilized and rabbit spermatozoa survived without apparent difficulty in the same oviduct. Survival of mouse spermatozoa was also poor in the rabbit. However, the time required for capacitation in this species is short, and some spermatozoa survived for a sufficient period to become capacitated, as judged by the fact that some eggs were fertilized. For these experiments, fresh epididymal mouse spermatozoa were 
incubated in the rabbit for $1-1.5 \mathrm{~h}$ before mouse egg transfer into the rabbit oviduct. When recovered $3 \mathrm{~h}$ after their transfer, 12 of 137 cumulus-intact, and 7 of 110 cumulus-free mouse eggs were penetrated. Despite the hostile environment, fertilization, and thus capacitation, did occur, albeit at a low level.

In the hamster oviduct, mouse gametes performed curiously (Table 2). Whereas about half of the cumulus-intact mouse eggs were fertilized consistently, none of the cumulus-free eggs was penetrated or fertilized in the hamster oviduct. To eliminate the possibility that a soluble factor(s) associated with mouse cumulus cells influenced sperm capacitation and/or egg penetrability, cumulus-free and -intact eggs were instilled into the same oviduct. The two egg populations were differentiated by labelling one population by brief exposure to fluorescein isothiocyanate (Overstreet, 1973), a procedure which does not impair fertilizability. The same result was obtained in this experiment, in which $15 / 28(54 \%)$ cumulus-intact, and $0 / 32$ cumulus-free eggs were penetrated, irrespective of which group was labelled. Since it has been suggested that cumulus cells promote capacitation (Gwatkin, Andersen \& Hutchinson, 1972), spermatozoa capacitated in vitro were employed to determine whether the use of such spermatozoa would overcome the absence of cumulus cells. The results of Exp. B (Table 2) demonstrated that this was not the case. Incubation in hyaluronidase to remove the cumulus cells did not interfere with mouse egg fertilizability in vivo, since 24/26 (92\%) cumulus-free mouse eggs were fertilized when transferred back into the mouse. Likewise, exposure to the hamster tract did not appear to cause an irreversible change in receptivity since cell-free eggs, recovered after $3 \mathrm{~h}$ in the hamster oviduct, were fully fertilizable when transferred subsequently into the mouse oviduct (24/30 eggs, $80 \%$ ) or when inseminated in vitro $(20 / 28 \mathrm{eggs}, 71 \%)$. This failure to fertilize the cumulus-free mouse egg in a foreign environment was not universal, however, since they could be fertilized in the rabbit (see above) and in the rat in which 38/45 (84\%) cumulus-intact, and 32/42 (76\%) cumulus-free mouse eggs were fertilized. Thus the refractoriness of the cell-free mouse egg in the hamster remains enigmatic.

\section{Discussion}

Capacitation remains as one aspect of mammalian sperm physiology that eludes precise definition. Strong circumstantial evidence suggests that it involves the sperm surface and also the pattern of motility, although whether capacitation in vitro involves the same changes that occur in the female tract has yet to be established. Three conclusions may be drawn from the present results. Firstly, capacitation, as well as gamete fusion, occurred without regard to the species of the female into which the gametes were instilled. Secondly, an environment that was suboptimal with respect to the maintenance of sperm motility was capable nevertheless of supporting capacitation and fertilization, as demonstrated by the fertilization of some mouse eggs in the rabbit oviduct despite the hostility of that environment toward mouse spermatozoa. Thirdly, when the environment was optimal, at oestrus, the time needed for capacitation was a function of the spermatozoon rather than of the environment. Based on the time of egg penetration after insemination in the homologous oviduct, mouse spermatozoa are capacitated in 1-2 h (P. M. Saling, unpublished results), hamster spermatozoa require 5-6 h (P. Viriyapanich, personal communication), and those of the rabbit about $10 \mathrm{~h}$ in the oviduct alone (Adams \& Chang, 1962). For a given species, approximately the same times were required in the present transfer experiments, regardless of the heterologous environment employed.

It should not be construed that there is no element of specificity in the relationship of spermatozoa with the female. Foreign spermatozoa inseminated into the vagina are often not transported to the site of fertilization; in certain combinations, furthermore, mammalian spermatozoa die within a short period in a foreign tract (Bedford, 1972). This is the case with mouse and hamster spermatozoa in the female tract of the rabbit. Because of the short period mouse spermatozoa require for capacitation, a small percentage of mouse eggs were fertilized 
when transferred to the rabbit oviduct $1 \mathrm{~h}$ after insemination with mouse spermatozoa, but no hamster eggs were fertilized in the rabbit, and mouse and hamster spermatozoa were immotile and mostly decapitate within $2 \mathrm{~h}$. Although the general conclusions of the studies are similar, de Mayo, Mizoguchi \& Dukelow (1980) have reported that a significant proportion of cumulus-intact hamster eggs may be fertilized in the rabbit oviduct. However, their results may have been due to parthenogenetic activation since the fertilizing sperm tail was not included in their criteria for fertilization.

While endocrine manipulations and other experimental studies suggest that capacitation in the female is mediated by distinct factors, their nature is unknown. The present study establishes that in the mouse, hamster and rabbit, these factors are not species specific; other reports of the fertilization of bovine gametes in the pig (Bedirian, Shea \& Baker, 1975), and of squirrel monkey gametes in the rabbit (de Mayo et al., 1980), suggest that this conclusion may be applied to mammals as a whole. A general conclusion that capacitation in vivo does not involve species-specific elements argues against the acquisition of molecules from female secretions by the sperm surface. Rather, it favours the concept that capacitation involves a loss of surface moieties, perhaps with a consequent re-ordering of the integral character of the plasmalemma (O'Rand, 1980).

We thank Dr R. G. Foldesy for help with several of the rabbit operations and Ms C. Greenberg for help with the manuscript preparation. This work has been funded by NIH grant No. HD-07257 to J.M.B. and by a Population Council post-doctoral fellowship to P.M.S.

\section{References}

Adams, C.E. \& Chang, M.C. (1962) Capacitation of rabbit spermatozoa in the fallopian tube and in the uterus. J. exp. Zool. 151, 159-165.

Austin, C.R. (1951) Observations on the penetration of sperm into the mammalian egg. Aust. J. Sci. Res. B4, 581-596.

Austin, C.R. (1952) The 'capacitation' of the mammalian sperm. Nature, Lond. 170, 326.

Barros, C. \& Berrios, M. (1977) Is the activated spermatozoon really capacitated? J. exp. Zool. 201, 65-72.

Bedford, J.M. (1972) Sperm transport, capacitation and fertilization. In Reproductive Biology, pp. 338-392. Eds H. Balin \& S. Glasser. Excerpta Medica, Amsterdam.

Bedford, J.M. \& Cross, N.L. (1978) Normal penetration of rabbit spermatozoa through a trypsin- and acrosin-resistant zona pellucida. J. Reprod. Fert. 54, 385-392.

Bedford, J.M. \& Shalkovsky, R. (1967) Speciesspecificity of sperm capacitation in the rabbit. $J$. Reprod. Fert. 13, 361-364.

Bedirian, K.N., Shea, B.F. \& Baker, R.D. (1975) Fertilization of bovine follicular oocytes in bovine and porcine oviducts. Can. J. Anim. Sci. 55, 251-256.

Chang, M.C. (1951) Fertilizing capacity of spermatozoa deposited in the Fallopian tubes. Nature, Lond. 168, 697.

Chang, M.C. \& Hancock, J.L. (1967) Experimental hybridization. In Comparative Aspects of Reproductive Failure, pp. 206-217. Ed. K. Benirschke. Springer, New York. de Mayo, F.J., Mizoguchi, H. \& Dukelow, W.R. (1980) Fertilization of squirrel monkey and hamster ova in the rabbit oviduct (Xenogenous fertilization). Science, N.Y. 208, 1468-1469.

Edwards, R.G. (1957) The experimental induction of gynogenesis in the mouse. 1. Irradiation of sperm by X-rays. Proc. R. Soc, B 146, 469-487.

Gwatkin, R.B.L., Andersen, O.F. \& Hutchinson, C.F. (1972) Capacitation of hamster spermatozoa in vitro: the role of cumulus components. J. Reprod. Fert. 30, 389-394.

Hunter, R.H.F. (1969) Capacitation in the golden hamster, with special reference to the influence of the uterine environment. J. Reprod. Fert. 20, 223-227.

O'Rand, M.G. (1980) Changes in sperm surface properties correlated with capacitation. In The Spermatozoon, Maturation, Motility, Surface Properties and Comparative Aspects, pp. 195-204. Eds D. W. Fawcett \& J. M. Bedford. Urban and Schwarzenberg, Baltimore.

Overstreet, J.W. (1973) The labelling of living rabbit ova with fluorescent dyes. $J$. Reprod. Fert. 32, 291-294.

Saling, P.M., Storey, B.T. \& Wolf, D.P. (1978) Calciumdependent binding of mouse epididymal spermatozoa to the zona pellucida. Devl Biol. 65, 515-525.

Toyoda, Y. \& Chang, M.C. (1974) Fertilization of rat eggs in vitro by epididymal spermatozoa and the development of eggs following transfer. J. Reprod. Fert. 36, 9-22.

Wolf, D.P. \& Inoue, M. (1976) Sperm concentration dependency in the fertilization and zonae binding properties of mouse eggs inseminated in vitro. J. exp. Zool. 196, 27-37. 